\title{
EDUCACORPOHUMANO3D: JOGO SÉRIO PARA O ESTUDO DO CORPO HUMANO NO ENSINO FUNDAMENTAL
}

\author{
JOGO SÉRIO EDUCACORPOHUMANO3D ${ }^{1}$
}

\author{
Gabriel B. Rombaldi ${ }^{1}$ \\ Patrícia J. Fiuza ${ }^{2}$ \\ Priscila M. S. Bilésimo ${ }^{1}$ \\ Robson R. Lemos ${ }^{2}$
}

\section{INTRODUÇÃO}

Pesquisa e desenvolvimento em jogos digitais apresentam diversas características interdisciplinares incluindo áreas de conhecimento, tais como, arte, cultura, saúde, educação e tecnologias da informação e comunicação. Quando os jogos são utilizados para promover algo além do entretenimento surge o termo conhecido como jogos sérios (MICHAEL; CHEN, 2005). Os jogos devem ser aplicados de forma lúdica, além disso os jogos sérios na educação consistem em jogos onde o principal objeto é a aprendizagem. $O$ uso de jogos sérios relacionado a saúde é uma área em constante evolução (WATTANASOONTORN et al., 2013). A utilização dos jogos sérios para auxiliar no repasse do aprendizado para o ensino fundamental, aplicado ao estudo dos sistemas do corpo humano, são instrumentos que motivam, atraem e estimulam o processo de construção do conhecimento. Podendo ser definido, de acordo com Soares (2004), como uma ação divertida, seja qual for o contexto linguístico, desconsiderando o objeto envolto na ação. Se há regras, essa atividade lúdica pode ser considerada um jogo sério. Neste trabalho será apresentado o projeto, a utilização e a análise de usabilidade de um ambiente educacional para estudar o corpo humano no ensino fundamental através de um jogo sério.

A seguir, neste trabalho serão relatados aspectos, tais como objetivos, revisão da literatura, metodologia, resultados, discussões e conclusões.

\footnotetext{
${ }^{1}$ JOGO SÉRIO EDUCACORPOHUMANO3D

1 Bacharel em Tecnologias da Informação e Comunicação da Universidade Federal de Santa Catarina - Centro Araranguá. Araranguá, Santa Catarina, Brasil.

${ }^{2}$ Professor da Universidade Federal de Santa Catarina - Centro Araranguá. Curso de Bacharelado e Pós-graduação em Tecnologias da Informação e Comunicação, Grupo de Pesquisa Mídia e Conhecimento (LabMídia). Araranguá, Santa Catarina, Brasil. (e-mail: robson.lemos@ufsc.br).
} 


\section{OBJETIVOS}

O principal objetivo deste trabalho é apresentar o jogo sério intitulado EducaCorpoHumano3D desenvolvido no Laboratório de Mídia e Conhecimento da UFSC para o estudo do corpo humano no ensino fundamental, assim como, as lições aprendidas durante a avaliação de usabilidade do jogo através de estudos de caso realizados em sala de aula. Desta forma, para este trabalho foi projetado e desenvolvido um ambiente de ensino e interação 3D baseado no conceito de jogos sérios e anatomia do corpo humano. Dentro deste contexto, estudos de casos foram planejados com o auxílio de técnicas de avaliação de usabilidade (CYBIS; BETIOL; FAUST, 2007) para verificar a qualidade de uso do jogo sério em sala de aula, assim como possíveis características que possam auxiliar no processo de aprendizagem a partir da utilização de jogos sérios no ensino fundamental.

\section{REVISÃO DA LITERATURA}

Jogo sério pode ser definido como um jogo de computador independente da tecnologia utilizada. Possui um objetivo divertido e desafiador para jogar ou envolver, incorporando normalmente, algum tipo de pontuação e transmitindo conteúdo educacional. Os jogos sérios foram inicialmente desenvolvidos para engenharia de desempenho humana, aplicações de jogos para saúde, políticas públicas e estratégicas, comunicação, sendo hoje aplicados a diversas áreas (MICHAEL; CHEN, 2005).

Como ferramenta de aprendizagem nas escolas os jogos sérios são adotados atualmente porque se destinam a ensinar aspectos que treinem habilidades operacionais e comportamentais específicas de uma disciplina em particular. As escolas apresentam hoje em dia uma forte tendência na utilização de jogos sérios em seus currículos. Essa adoção está acontecendo de forma muito lenta, porque necessitam de incentivos governamentais para diminuir barreiras como integração do currículo, capacitações dos professores, laboratórios de informática estruturados, o acesso à internet e projetos que se destinem a utilizar os jogos sérios como estratégia de ensino (LEMES, 2014).

Os sistemas do corpo humano são abordados na matéria de ciências e são estudados entre o quinto e sexto ano do ensino fundamental. Nestes estudos os sistemas do corpo humano são abordados a partir da apresentação das 
características principais dos órgãos humanos. Os órgãos são estruturas formadas por diferentes tecidos. Cada órgão desempenha uma ou mais funções no organismo. Um conjunto de órgãos que realiza uma função específica no corpo forma um sistema. O nosso corpo é formado por vários sistemas e são eles: digestório, cardiovascular, respiratório, urinário, nervoso, esquelético, muscular, articular, genital, órgãos dos sentidos e glândulas endócrinas. Para que nosso organismo seja considerado saudável e funcione de forma equilibrada e harmoniosa, todos os sistemas devem exercer suas funções de maneira integrada (GIL; FANIZZI, 2011).

Dentro do contexto de jogos sérios, neste trabalho três sistemas do corpo humano são abordados, tais como: respiratório, esquelético e digestório.

\section{METODOLOGIA}

Neste trabalho foram realizados estudos teórico-empíricos apoiados em implementações, experimentos e estudos de caso. Inicialmente foi realizada uma pesquisa bibliográfica com ênfase nos principais conceitos associados a jogos sérios e ambientes educacionais para o ensino de ciências aplicadas no estudo do corpo humano no ensino fundamental. Para desenvolver o projeto do jogo sério utilizou-se a metodologia de Aprendizagem Baseada em Jogo Digital (DBGL) (ZIN et al., 2009). Pesquisadores acreditam que a DBGL tem o potencial de ajudar a superar problemas de aprendizagem. Para o desenvolvimento do jogo utilizou-se a biblioteca de desenvolvimento de jogos conhecida como Unity 3D (UNITY, 2016). O ambiente de ensino e interação, jogo sério EducaCorpohumano3D foi aplicado no ensino fundamental em duas instituições públicas, sendo o $5^{\circ}$ ano da Escola de Educação Básica Municipal 12 de maio, e para $\circ 6^{\circ}$ ano da Escola de Educação Básica Eufrázio Avelino Rocha. Ambas escolas são localizadas no município de Maracajá no sul de Santa Catarina. Inicialmente entrou-se em contato com as professoras responsáveis pela disciplina de ciências para verificar a disponibilidade de aplicar o jogo EducaCorpoHumano3D no laboratório de informática da escola. Após o aval das professoras e da direção das instituições de ensino foi realizada uma sessão de estudo do corpo humano com o auxílio do jogo EducaCorpoHumano3D e posteriormente a avaliação de usabilidade através de um questionário de satisfação realizado pelos estudantes e professoras. Para a avaliação do jogo sério EducaCorpoHumano3D, foi adotado uma metodologia de avaliação adequada e 
específica para crianças e adolescentes (BORGERS et al., 2002).

\section{RESULTADOS E DISCUSSÃO}

A partir dos conceitos apresentados na metodologia de Borgers et al. (2002), Read (2006) desenvolveu um instrumento intitulado "Fun Toolkit (v3)", o qual conta com um kit de ferramentas para avaliação. Estas ferramentas são utilizadas no questionário desenvolvido neste trabalho para avaliação do jogo sério. As ferramentas usadas para avaliação foram o Smileyometer e a Again Again Table. $O$ Smileyometer é apresentado em uma linha horizontal com opções correspondentes a desenhos de faces, onde a criança é convidada para assinalar uma das opções conforme seu sentimento. Este método foi criado com o objetivo de identificar como a criança está se sentindo em relação ao que foi proposto. O Smileyometer apresenta uma interface com desenho de faces que representam sentimentos de "ruim", "não muito bom", "bom", "muito bom" e "ótimo". A Again Again Table é uma tabela simples que requer que a criança assinale uma das opções seja "Sim", "Talvez" ou "Não" considerando a pergunta se a criança gostaria de jogar o EducaCorpoHumano3D novamente. O conceito principal desta ferramenta vem do trabalho da psicologia que apoia a ideia de que estamos mais propensos a voltar a uma atividade que gostamos de realizar. Salas com computadores foram preparadas para que os alunos pudessem utilizar e avaliar o jogo sério EducaCorpoHumano3D. Inicialmente foi apresentado o plano de aula, preparado à turma e entregue a professora um questionário, para que fosse preenchido após a avaliação da utilização do jogo com os alunos. No término da utilização do jogo foi solicitado aos alunos que preenchessem um questionário de satisfação (CYBIS; BETIOL; FAUST, 2007) fazendo uso do Smileyometer e da Again Again Table. Na turma do $5^{\circ}$ ano foi aplicado o questionário para 18 crianças/adolescentes, com idades entre 9 anos a 12 anos. Dos 18 alunos, 9 eram do sexo masculino e 9 do sexo feminino. Dentro do requisito satisfação $94,4 \%$ responderam que o jogo estava ótimo e 5,6\% responderam que o jogo estava muito bom. Logo no requisito sobre se jogariam novamente, $88,9 \%$ responderam que jogariam outra vez e somente $11,1 \%$ talvez voltassem a jogar. Na turma do $6^{\circ}$ ano o questionário foi respondido por 18 crianças/adolescentes, com idades entre 10 anos a 13 anos. Dos 18 alunos, 14 eram do sexo masculino e 4 do sexo feminino. Analisando o requisito de satisfação, 94,4\% responderam que o jogo estava ótimo e apenas $5,6 \%$ responderam que estava muito 
bom. No requisito onde se questionava sobre se jogariam novamente $94,4 \%$ responderam que jogariam novamente e apenas $5,6 \%$ responderam que talvez. 0 questionário respondido pelas professoras envolveu critérios sobre, aspectos do jogo, sugestões, motivação de aprendizagem entre os alunos e se apresentavam o interesse em aplicar o jogo novamente para a classe. A primeira professora, da turma do $5^{\circ}$ ano, relatou que o jogo EducaCorpoHumano3D, foi muito bom para sair do cotidiano da aula, onde os alunos ficam normalmente em torno da lousa e dos cadernos. A segunda professora, da turma do $6^{\circ}$ ano, descreveu que os melhores aspectos do jogo EducaCorpoHumano3D foram os modelos em 3D e a variedade de perguntas.

\section{CONCLUSÃO}

No geral os alunos tiveram facilidade de interagir com o módulo de ensino e perguntas do jogo sério. A possibilidade de visualizar os modelos sob diferentes pontos de vista no ambiente 3D foi bem recebida pelos alunos. Observou-se durante a utilização do jogo por parte dos alunos que apesar da maioria apresentar facilidade na utilização do jogo, a grande maioria não dedicou o tempo necessário para a leitura das instruções do jogo. As professoras que participaram na avaliação do jogo, afirmaram que através das tecnologias interativas o interesse em estudar mais vezes o assunto é despertado no aluno, assim como o aprendizado se torna mais rápido e mais prazeroso.

\section{REFERÊNCIA}

BORGERS, N.; HOX, J.; SIKKEL, D. Response quality in research with children and adolescents: the effect of labelled response opinions and vague quantifiers. International Journal of Public Opinion Research. ago. 2002, vol. 15, no. 1 , p. 83-94.

CYBIS, W.; BETIOL, A.; FAUST, R. Ergonomia e Usabilidade: conhecimento, métodos e aplicações. São Paulo: Novatec, 2007.

GIL, A. B. A.; FANIZZI, S. Nosso Corpo: organização e funcionamento: Sistemas. In: GIL, A. B. A.; FANIZZI, S. Porta Aberta: Ciências. São Paulo: Ftd, 2011. p. 107121.

LEMES, D. O. Serious games - jogos e educação. São Paulo, 2014. Disponível em:<http://www.abrelivros.org.br/home/index.php/bienal-2014/resumos-e-fotos/5647primeiro-resumo>. Acesso em: 10 junho 2016. 
MICHAEL, D. R.; CHEN, S. L. Serious Games: Games that educate, train, and inform. New York: Cengage Learning Ptr, 2005.

READ, J. C. Validating the Fun Toolkit: an instrument for measuring children's opinions of technology. Cognition, Technology \& Work. abr. 2008, vol. 10, no. 2, p. 119-128.

SOARES, M. H. F. B. O lúdico em química: jogos e atividades aplicados ao ensino de química. Tese (Doutorado em Ciências), Universidade Federal de São Carlos, São Paulo, 2004.

UNITY. Unity Game Engine. 2005. Disponível em: <https://unity3d.com/pt>. Acesso em: 10 Junho 2016.

WATTANASOONTORN, V. et al. Serious games for health. Entertainment Computing, dez. 2013, vol. 4, no. 4, p.231-247.

ZIN, NOR AZAN MAT, et al. Digital Game-based learning (DGBL) model and development methodology for teaching history. WSEAS Transactions on Computers. fev. 2009, vol. 8, no. 2, p.322-333. 